\title{
PENGARUH CUSTOMER RELATIONSHIP MANAGEMENT (CRM) TERHADAP PRODUCT KNOWLEDGE DAN LOYALTY INTENTION PADA NASABAH PT. BANK BNI SYARIAH CABANG MATARAM
}

\author{
Magma Zulfiqar Ismail ${ }^{1}$, Sulhaini ${ }^{2}$, Handry Sudiartha Athar ${ }^{3}$ \\ 1Program Studi Magister Manajemen Fakultas Ekonomi Dan Bisnis Unram. \\ Email: magma.askridasyariah@gmail.com \\ 2Fakultas Ekonomi dan Bisnis Unram. Email :niniys@yahoo.co.uk \\ ${ }^{3}$ Fakultas Ekonomi dan Bisnis Unram. Email : andre_sudiartha@yahoo.com
}

\begin{abstract}
ARTICLE INFO
Keywords :

Customers

Relationship

Management (CRM), Product

Knowledge dan Loyalty Intention

How to cite :

Zulfikar Ismail, Magma., Sulhaini., Sudiartha Athar, Handry., (2019). Pengaruh Customer Relationship Management (CRM) terhadap Product Knowledge dan Loyalty Intention pada Nasabah PT. Bank BNI Syariah Cabang Mataram. JMM UNRAM, 8(3), 212-224
\end{abstract}

DOI :

http://dx.doi.org/10.29303/jmm.v8i3

$\begin{array}{ll}\text { Dikumpulkan } & \text { : 27 Juni } 2019 \\ \text { Direvisi } & \text { :05 Juli } 2019 \\ \text { Dipublikasi } & : 08 \text { Juli } 2019\end{array}$

\section{ABSTRACT}

This study aims to determine the effect of Customer Relationship Management on Product Knowledge and Customer Loyalty Intention PT. Bank BNI Syariah Mataram Branch. And to find out the effect of Product Knowledge on Customer Loyalty Intention, PT. Bank BNI Syariah Mataram Branch. The type of research used is causality with a non purposive sampling technique. The population in this study is the customer of PT. Bank BNI Syariah Mataram Branch in the past year amounted to 100 respondents with data collection techniques using questionnaires. Data analysis uses path analysis with the help of Structural Equation Modeling (SEM) with AMOS Software.

The results of the study show that; Customers Relationship Management (CRM) has a positive and significant effect on Product Knowledge at the BNI BNI Syariah Bank Branch. Product Knowledge has a positive and significant influence on consumer Loyalty Intention at the BNI BNI Syariah Bank Branch. Customers Relationship Management (CRM) has a positive and significant influence on consumer Loyalty Intention at the BNI BNI Syariah Bank Branch.

Penelitian ini bertujuan untuk mengetahui pengaruh Customer Relationship Management terhadap Product Knowledge dan Loyalty Intention Nasabah PT. Bank BNI Syariah Cabang Mataram. Serta untuk mengetahui pengaruhProduct Knowledge terhadap Loyalty Intention Nasabah PT. Bank BNI Syariah Cabang Mataram. Jenis penelitian yang digunakan adalah kausalitas dengan teknik non purposive sampling. Populasi dalam penelitian ini adalah Nasabah PT. Bank BNI Syariah Cabang Mataram dalam setahun terakhir berjumlah 100 responden dengan teknik pengumpulan data menggunakan kuesioner. Analisis data menggunkan analisis jalur dengan bantuan Structural Equation Modeling (SEM) dengan Software AMOS.

Hasil penelitian menunjukkan bahwa; Customers 
Relationship Management (CRM) berpengaruh positif dan signifikan terhadap Product Knowledge pada Bank BNI Syariah Cabang Mataram. Product Knowledge memiliki pengaruh yang positif dan signifikan terhadap Loyalty Intention konsumen pada Bank BNI Syariah Cabang Mataram. Customers Relationship Management (CRM) memiliki pengaruh yang positif dan signifikan terhadap Loyalty Intention konsumen pada Bank BNI Syariah Cabang Mataram.

Copyright $\odot 2019$ JMM UNRAM. All rights reserved.

\section{PENDAHULUAN}

\subsection{Latar Belakang}

Industri perbankan kini mulai menyadari, pelanggan tidak hanya mempertimbangkan faktor bunga, serta berbagai fitur utama dari layanan produk perbankan semata, melainkan yang di harapkan nasabah adalah memperoleh nilai atau manfaat tambahan dari apa yang ditawarkan tersebut dibandingkan produk pesaing, sehingga pada akhirnya konsumen tersebut bersedia untuk menjadi konsumen yang loyal (Bielen et al., 2007). Untuk mendapatkan konsumen yang loyal, maka harus didukung dengan strategi menciptakan hubungan (relationship) antara pihak perusahaan dengan pelanggan. Meskipun demikian, sebagian besar perbankan telah melakukan upaya terbaik untuk meningkatkan implementasi CRM dalam memenuhi kebutuhan nasabah termasuk memberikan informasi tentang pengetahuan (knowledge) berbagai fitur serta atribut produk yang ditawarkan. Namun, beberapa perusahaan di bidang jasa belum mengetahui secara pasti berapa banyak pelanggan yang merasakan efek dari implementasi CRM yang diterapkan (Satria, 2013).

CRM dapat berpengaruh terhadap niat konsumen untuk loyal. Menurut Supriadi, (2014) hubungan yang baik dengan konsumen akan membuat konsumen cenderung loyal terhadap produk perusahaan. Penelitian Arif \& Nurasiah (2015), Rahmadewi, et.al (2015), membuktikan bahwa customer relationship management berpengaruh terhadap kecenderungan nasabah untuk berperilaku loyal. Penelitian Oktariana, Fauzi, Kumadji. 2010 dengan menggunakan 10 indikator CRM (Identifikasi, Diferensiasi, Interaksi, Customize, Berbagi informasi, Keterlibatan Pelanggan, Kemitraan jangka panjang, Pemecahan masalah bersama, Teknologi berbasis CRM, Otomatisasi dan Layanan). Hasil penelitian menunjukan tidak terdapat pengaruh langsung yang signifikan dari CRM terhadap Loyalitas konsumen. Ariyanti, 2006 dengan menggunakan 5 indikator CRM (Developing customer insight, Use oftechnology in CRM, Customer contact, Personalizing Customer interaction, Achieving Superior Customer Experience) hasil penelitian menunjukan bahwa kelima indikator tersebut belum cukup mampu menciptakan hubungan yang erat dengan pelanggan dan membuat konsumen untuk loyal. Sementara penelitian Maftuhah et al.,2014 dengan mengunakan 4 indikator CRM (Karyawan, Teknologi, Penjualan dan Produk) berpengaruh positif dan signifikan terhadap loyalitas nasabah.

Lebih lanjut, penelitian Widodo, 2011 dengan mengunakan 4 indikator CRM (Identifikasi, diferensiasi, interaksi, dan customize) baik secara parsial maupun simultan berpengaruh positif dan signifikan terhadap loyalitas nasabah. Sementara penelitian Fanani dkk, .2014 mengukur loyalitas konsumen dengan menggunakan 4 indikator CRM dari Robinette (2001:125) seperti keuntungan bersama, komitmen, kebenaran dan komunikasi. Hasil penelitian menunjukkan indikator keuntungan bersama, komitmen, kebenaran dan komunikasi berpengaruh secara simultan terhadap loyalitas. Namun secara parsial hanya indikator komitmen yang berpengaruh secara tidak signifikan terhadap loyalitas. Penelitian yang dilakukan oleh Mokodongan (2010), membuktikan bahwa 
penerapan program CRM pengaruhnya sangat rendah terhadap loyalitas pelanggan. Dari hasil penelitian terdahulu tersebut terdapat berbedaan hasil penelitian serta indikator yang digunakan sehingga menjadi celah untuk dilakukan penelitian kembali.

Studi tentang perilaku nyata dari seseorang pada umumnya menganggap bahwa antara niat (intentions) dan tindakan (behavior) mempunyai hubungan yang kuat, dan perilaku dapat diprediksi berdasarkan niatnya (Ajzen, 2002). Isnani (2014) dan Suryanda (2016), pengetahuan nasabah berpengaruh terhadap keputusan nasabah dalam menabung di bank syariah. Namun hasil penelitian Yuliawan (2011), pengetahuan konsumen tentang produk bank syariah memberikan pengaruh sangat kecil terhadap pengambilan keputusan untuk menjadi nasabah pada bank syariah. Safrida (2015), pengetahuan produk oleh konsumen tidak berpengaruh pada keinginan konsumen untuk menjadi konsumen yang loyal, Rizkiana (2009) dan Octaviani (2017), product knowledge tidak berpengaruh signifikan terhadap keputusan konsumen. Dari beberapa hasil penelitian tersebut terdapat hasil penelitian yang tidak seragam atau tidak konsisten sehingga diperlukan pengkajian secara lebih lanjut.

Penerapan sistem CRM pada Bank BNI syariah sendiri tidak terlepas dari permasalahan-permasalahan yang muncul. Permasalahan yang dihadapi bank BNI syariah saat ini adalah pertama, masih kuatnya budaya sistem perbankan lama yang memberikan hasil lebih pasti (berupa bunga), dibanding perbankan syariah yang returnnya tergantung pada hasil yang diterima oleh Bank. Kedua, masih rendahnya sosialisasi yang dilakukan oleh bank syariah mataram terkait produk-produk syariah unggulan. Ketiga, masalah hukum berkaitan dengan UU yang mengatur operasional bank syariah, serta tidak ada badan yang jelas untuk menyelesaikan perkara antara pihak bank dengan nasabah. Keempat, kendala operasional berkaitan dengan masih kurangnya sumber daya manusia serta keahlian di bidang perbankan syariah lain-lain. Kelima adalah kendala teknologi, perusahaan dituntut untuk melakukan inovasi dan meng upgrade secara terus menerus perkembangan teknologi yang terus berubah setiap saat. Tujuan yang ingin diketahui dalam penelitian ini adalah untuk menguji pengaruh CRM, terhadap Product Knowledge dan Loyalty Intention.

\section{TINJAUAN PUSTAKA}

\subsection{Hubungan Antar Variabel dan Pengembangan Hipotesis Penelitian}

\subsubsection{Hubungan Customer Relationship Management terhadap Product Knowledge}

Penelitian terbaru yang dilakukan oleh Gartner Research Group di Amerika Utara menemukan bahwa 55\% dari semua proyek CRM gagal memberikan hasil yang diharapkan (Rigby et al., 2002 dalam Alexandra, 2003). Masih dalam penelitian yang sama, hasil studi oleh Ernst \& Young (2001) dari para manajer yang telah menerapkan CRM menemukan bahwa dua tantangan terbesar dalam menerapkan strategi CRM adalah isu organisasi internal (53\% responden), diikuti oleh kemampuan untuk mengakses semua informasi yang relevan (40\% responden). Ini menunjukkan bukti bahwa agar CRM berhasil, diperlukan perubahan bagaimana cara perusahaan mengelola informasi pelanggan secara internal. Beberapa perusahaan mengetahui cukup banyak tentang perilaku pelanggan tetapi masih sedikit di antara mereka mengetahui tentang bagaimana perusahaan mengunakan pengetahuan pelanggan tentang suatu produk dengan baik. Dengan kata lain, apabila perusahaan mampu menjaga manajemen hubungan pelanggan dengan baik dengan menyediakan berbagai informasi produk yang lengkap untuk konsumennya, maka pengetahuan konsumen akan produk yang ditawarkan akan semakin meningkat sehingga pada akhirnya dapat mengarahkan konsumen untuk berperilaku loyal. Berkaitan dengan hal tersebut maka dapat diajukan hipotesis pertama yaitu; 
$\mathrm{H}_{1}$ : Semakin baik Customer Relationship Management (CRM) di implementasikan maka akan semakin tinggi pula Product Knowledge nasabah pada PT. Bank BNI Syariah Cabang Mataram.

\subsubsection{Hubungan Customer Relationship Management terhadap Loyalty Intention}

Kotler dan Armstrong (2008), berpendapat bahwa Customer Relationship Management (CRM) dapat membangun dan memelihara hubungan pelanggan yang menguntungkan dengan menghantarkan nilai dan menciptakan pelanggan yang loyal dengan berbagai keunggulan produk yang ditawarkan. Sementara menurut Bob Foster 2008, menyatakan bahwa Fokus dari Customer Relationship Management (CRM) salah satunya untuk meningkatkan keputusan pembelian konsumen, apabila konsumen terus melakukan pembelian maka berpotensi untuk menjadi konsumen yang loyal.

Kajian empiris oleh Ahrari dan Amirusefi (2012) hasil penelitian menunjukkan bahwa ada hubungan yang signifikan antara Customer Relationship Management (CRM) dan loyalitas konsumen. Penelitian Rahmadewi, et.al (2015), membuktikan bahwa Customer Relationship Management (CRM) berpengaruh signifikan terhadap keputusan pembelian ulang konsumen. Dimana, ketika konsumen melakukan pembelian ulang secara terus menerus dapat mengarah pada kecenderungan niat konsumen untuk menjadi pembeli yang loyal. Pada penelitian Maftuhah, et.al (2014), membuktikan bahwa Customer Relationship Management (CRM) berpengaruh terhadap loyalitas nasabah. Sedangkan hasil penelitian Arif \& Nurasiah (2015), membuktikan bahwa Customer Relationship Management (CRM) berpengaruh terhadap loyalitas nasabah bank. Penelitian Rahayu \& Suryanti (2014), membuktikan bahwa hubungan pelanggan berpengaruh terhadap loyalitas nasabah. Berkaitan dengan hal tersebut dapat diajukan hipotesis kedua sebagai berikut;

$\mathrm{H}_{2}$ : Semakin tinggi Customer Relationship Management (CRM) maka akan semakin tinggi pula Loyalty Intention nasabah pada PT. Bank BNI Syariah Cabang Mataram.

\subsubsection{Hubungan Product Knowledge dengan Loyalty Intention}

Pengetahuan produk yang dimiliki oleh konsumen sangat mempengaruhi dalam membeli suatu produk. Semetara Menurut Durianto, et.al (2001), pengetahuan yang dimiliki oleh nasabah sangat mempengaruhi sikap dan prilaku nasabah dalam mengambil sebuah keputusan, karena semakin tinggi tingkat pengetahuan tentang produk, berarti produk tersebut berada dalam benak konsumen sebelum adanya produk lain sehingga pengetahuan nasabah akan mempengaruhi keputusan pembelian. Sieben yang dikutip dalam Waluyo dan Pamungkas (2003), pengetahuan produk adalah cakupan seluruh informasi akurat yang disimpan dalam memori konsumen yang sama baiknya dengan persepsinya terhadap pengetahuan produk. Konsumen dengan pengetahuan yang lebih tinggi akan menjadi lebih realistis dalam pemilihan produk yang sesuai dengan harapannya. Dimana, semakin tinggi pengetahuan konsumen dalam pembelian suatu produk, dapat meningkatkan kemampuan konsumen untuk membuat pilihan yang lebih memuaskan.

Hasil penelitian terdahulu yang dilakukan oleh Kuncahyaningtyas dan Amron, (2015), bahwa terdapat pengaruh yang positif dan signifikan antara pengetahuan produk terhadap niat konsumen untuk kembali menggunakan jasa perbankan, dimana niat berperilaku cenderung dapat mengarahkan konsumen untuk berperilaku loyal. Penelitian Isnani (2014) dan Suryanda (2016), membuktikan bahwa pengetahuan nasabah berpengaruh terhadap keputusan nasabah dalam menabung di bank syariah. Namun dalam penelitian Yuliawan (2011), pengetahuan konsumen tentang bank syariah memberikan pengaruh sangat kecil terhadap pengambilan keputusan konsumen untuk menjadi nasabah pada bank syariah. Sementara, penelitian yang dilakukan oleh Safrida 


\section{NATIONALLY ACCREDITED J OURNAL = DECREE NO. 21/E/KPT/2018}

(2015), pengetahuan produk oleh konsumen tidak berpengaruh pada niat konsumen untuk loyal. Demikian halnya dengan penelitian Rizkiana (2009) dan Octaviani (2017), justru membuktikan bahwa product knowledge tidak berpengaruh signifikan terhadap keputusan konsumen. Berdasarkan uraian tersebut maka dapat diajukkan hipotesis ketiga yaitu;

$\mathrm{H}_{3}$ : Semakin tinggi Product Knowledge maka akan semakin tinggi pula Loyalty Intention pada PT. Bank BNI Syariah Cabang Mataram.

\section{METODOLOGI PENELITIAN}

\subsection{Jenis dan populasi Penelitian}

Penelitian ini menggunakan jenis penelitian kausalitas. Menurut Ferdinand, (2014) penelitian kausalitas adalah penelitian yang ingin mencari penjelasan bentuk hubungan sebab-akibat (Cause-effect) antar beberapa konsep atau beberapa variabel penelitian. Jenis penelitian kausalitas yang digunakan dalam penelitian ini diharapkan akan memberikan rumusan untuk menemukan pengaruh variabel Customer Relationship Management terhadap Product Knowledge, dan Loyalty Intention nasabah (studi kasus pada PT. Bank BNI Syariah Cabang Mataram). Populasi pada penelitian ini adalah seluruh nasabah PT. Bank BNI Syariah Cabang Mataram. Sampel dalam penelitian ini sebanyak 100 nasabah.

\subsubsection{Deskripsi Identitas Responden Penelitian}

Dalam penelitian ini dibagikan kuesioner sebanyak 100. Kuesioner yang disebar menggunakan teknik wawancara terbuka dan tertutup. Karakteristik responden penelitian berdasarkan Jenis Kelamin, Usia, Tingkat Pendidikan dan pekerjaan dapat digambarkan sebagai berikut.

Tabel 1: Profil Responden Penelitian terdiri dari Usia, Jenis Kelamin, Tingkat Pendidikan dan Pendapatan

\begin{tabular}{|l|l|r|r|}
\hline \multicolumn{2}{|c|}{ Profil Responden } & Jumlah (Orang) & Persentase (\%) \\
\hline \multirow{5}{*}{ Usia (Tahun) } & $<20$ Tahun & 48 & 48.0 \\
\cline { 2 - 4 } & 21-30 Tahun & 31 & 31.0 \\
\cline { 2 - 4 } & $31-40$ Tahun & 12 & 12.0 \\
\cline { 2 - 4 } & $>40$ Tahun & 9 & 9.0 \\
\cline { 2 - 4 } & Total & $\mathbf{1 0 0}$ & $\mathbf{1 0 0 . 0}$ \\
\hline \multirow{5}{*}{ Tenis Kelamin } & Laki-laki & 43 & 43.0 \\
\cline { 2 - 4 } & Wanita & 57 & 57.0 \\
\cline { 2 - 4 } & Total & $\mathbf{1 0 0}$ & $\mathbf{1 0 0 . 0}$ \\
\hline \multirow{5}{*}{ Tingkat Pendidikan } & SMA & 48 & 48.0 \\
\cline { 2 - 4 } & Diploma Tiga (D3) & 32 & 32.0 \\
\cline { 2 - 4 } & Srata Dua (S2) & 13 & 13.0 \\
\cline { 2 - 4 } & Srata Tiga (S3) & 7 & 7.0 \\
\cline { 2 - 4 } & Total & $\mathbf{1 0 0}$ & $\mathbf{1 0 0 . 0}$ \\
\hline \multirow{5}{*}{ Pendapatan Perbulan } & Pelajar & 36 & 36.0 \\
\cline { 2 - 4 } & Mahasiswa & 55 & 55.0 \\
\cline { 2 - 4 } & Swasta & 9 & 9.0 \\
\cline { 2 - 4 } & Total & $\mathbf{1 0 0}$ & $\mathbf{1 0 0 . 0}$ \\
\hline & $<500.000,-$ Perbulan & 41 & 41.0 \\
\cline { 2 - 4 } & $500.000,-$ Rp 1. 000.000,- Perbulan & 39 & 39.0 \\
\cline { 2 - 4 } & Rp 1.000.000,- Perbulan & 20 & 20.0 \\
\cline { 2 - 4 } & Total & $\mathbf{1 0 0}$ & $\mathbf{1 0 0 . 0}$ \\
\hline \multirow{3}{*}{ Lama Menjadi Nasabah } & $<6$ Bulan & 32 & 32.0 \\
\cline { 2 - 4 } & $>6-12$ Bulan & 68 & 68.0 \\
\cline { 2 - 4 } & Total & $\mathbf{1 0 0}$ & $\mathbf{1 0 0 . 0}$ \\
\hline
\end{tabular}

(Sumber; data primer diolah) 


\section{NATIONALLY ACCREDITED J OURNAL = DECREE NO, 21/E/KPT/2018}

\subsection{Uji Instrumen Penelitian}

\subsubsection{Uji Validitas}

Untuk mengetahui validitas setiap indikator dapat melihat nilai dari Faktor Loading setiap variabel yang diteliti. Hair at all, (2010) uji validitas dapat terpenuhi apabila nilai Loading Faktor di atas 0,5. Pada penelitian ini nilai factor loading di atas dari 0,5.

Tabel 2.

Hasil Loading Faktor Unstandrized SEM

\begin{tabular}{|c|c|c|}
\hline Variabel Dan Indikator & Lodiang Faktor & Keterangan \\
\hline \multicolumn{3}{|l|}{ Customer Relationship Management $(\mathrm{X})$} \\
\hline Perlindungan privasi $\left(\mathrm{X}_{1.1}\right)$ & 0,64 & Valid \\
\hline Differentiation $\left(\mathrm{X}_{1.2}\right)$ & 0,71 & Valid \\
\hline Customization $\left(\mathrm{X}_{1.3}\right)$ & 0,81 & Valid \\
\hline Interaksi (Interaction) $\left(\mathrm{X}_{1.4}\right)$ & 0,86 & Valid \\
\hline Teknologi (Technology) $\left(\mathrm{X}_{1.5}\right)$ & 0,80 & Valid \\
\hline \multicolumn{3}{|l|}{ Product Knowledge $\left(\mathrm{Y}_{1}\right)$} \\
\hline Subjective knowledge (Y1.1), & 0,69 & Valid \\
\hline Objective knowledge (Y1.2); & 0,87 & Valid \\
\hline Experience-based knowledge (Y1.3), & 0,80 & Valid \\
\hline \multicolumn{3}{|l|}{ Loyalty Intention $(\mathrm{Y} 2)$} \\
\hline Komitmen (Y2.1); & 0,63 & Valid \\
\hline Melakukan pembelian secara berulang (Y2.2); & 0,77 & Valid \\
\hline Kesediaan untuk membayar lebih (Y2.3); & 0,84 & Valid \\
\hline Memberi saran (Y2.4); & 0,71 & Valid \\
\hline
\end{tabular}

(Sumber; data primer diolah)

Dari tabel 2 ditemukan bahwa seluruh indikator yang berjumlah 12 telah memenuhi uji validitas instrumen karena nilai faktor loading dari masing-masing indikator atau konstruk telah memnuhi standar nilai validitas yang di persyaratkan.

\section{a. Uji Kaiser Meyer Olkin (KMO) dan Bartlett's Test}

Uji ini dilakukan untuk mengetahui seberapa layak data yang dimiliki untuk dianalisis lebih lanjut. Uji Kaiser Meyer Olkin (KMO) and Bartlett's Test merupakan statistik yang dapat menjelaskan tentang proporsi keragaman pada setiap variabel common variance (butir pertanyaan dalam kuesioner) atau keragaman yang disebabkan oleh faktor tertentu (underlying factor) dan cocok digunakan pada penelitian yang relatif baru dan belum memiliki teori yang kuat. Nilai Batas kelayakan harus diatas 0.5 dengan signifikansi $<0.05$ supaya variabel bisa diprediksi dan dapat dianalisis lebih lanjut.

Tabel 3. Hasil KMO and Bartlett's Test KMO and Bartlett's Test

\begin{tabular}{|c|c|c|}
\hline Kaiser-Meyer-Olkin Measu & Sampling Adequacy. & .838 \\
\hline Bartlett's Test of Sphericity & Approx. Chi-Square & 602.598 \\
\hline & df & \\
\hline & Sig. & .000 \\
\hline
\end{tabular}

(Sumber; data primer diolah)

Berdasarkan hasil Hasil KMO and Bartlett's Test yang telah dilakukan menunjukkan bahwa butir-butir penyataan dalam penelitian ini sudah layak dianalisis lebih lanjut karena Nilai Batas kelayakan diatas 0.5 dengan signifikansi $<0.05$ atau 0,000.

\subsubsection{Uji Reliabilitas}

Uji reliabilitas berkaitan dengan pengukuran yang dibuktikan dengan menguji konsistensi dan stabilitas. Uji reliabilitas diartikan sebagai tingkatan dimana pengukuran yang digunakan bebas dari random error dan memiliki hasil yang konsisten. Uji reliabilitas 


\section{NATIONALLY ACCREDITED J OURNAL = DECREE NO. 21/E/KPT/2018}

dalam penelitian ini dapat dilihat berdasarkan nilai Crombahch's Alfa. Cronbach's Alpha merupakan sebuah ukuran keandalan yang memiliki nilai berkisar dari nol sampai satu (Hair et al., 2010). Nilai keandalan konstruk minimum adalah sebesar 0,7 (Hair et al., 2010).

Tabel 4. Hasil Uji Reliabilitas Variabel Penelitian

\begin{tabular}{|l|c|c|}
\hline \multicolumn{1}{|c|}{ Variabel } & Nilai Crombahch's Alfa & Keterangan \\
\hline Customer Relationship Management (X) & 0.873 & Reliabel \\
\hline Product Knowledge ( $\left.\mathrm{Y}_{1}\right)$ & 0.829 & Reliabel \\
\hline Loyalty Intention (Y2) & 0.826 & Reliabel \\
\hline (Sumber; data primer diolah)
\end{tabular}

Berdasarkan tabel 3.5 menunjukan bahwa ketiga variabel penelitian memiliki nilai Crombahch's Alfa di atas 0,7 sehingga dapat dikatakan telah memenuhi uji reliabililitas dan di katakan reliable.

\section{HASIL DAN PEMBAHASAN}

Dalam penelitian ini peneliti menggunakan empat variabel utama yaitu Custromers Relationship Management, Product Knowledge dan Loyalty Intention. Item-tem pernyataan untuk variabel tersebut di sebarkan melalui kuesioner atau angket kepada 100 responden.

\subsection{Analisis Data Penelitian}

Untuk mengetahui pengaruh antar variabel yang telah dirumuskan dalam hipotesis penelitian, dalam penelitian ini mengunakan analisis jalur dengan bantuan SEM dengan software Amos Versi 20.

Berdasarka pengujian kelayakan model secara keseluruhan dapat dikatakan baik dan memenuhi kriteria Goodness-Off-Fit atau memenuhi syarat Cut-Off-Value yang ditentukan. Sehingga dapat disimpulkan bahwa konstruk-konstruk yang digunakan dalam penelitian ini sudah mencerminkan variabel laten endogen (Customers Relationship Management) serta variabel laten eksogen (Product Knowledge dan Loyalty Intention) yang di analisis berserta masing-masing indikator.

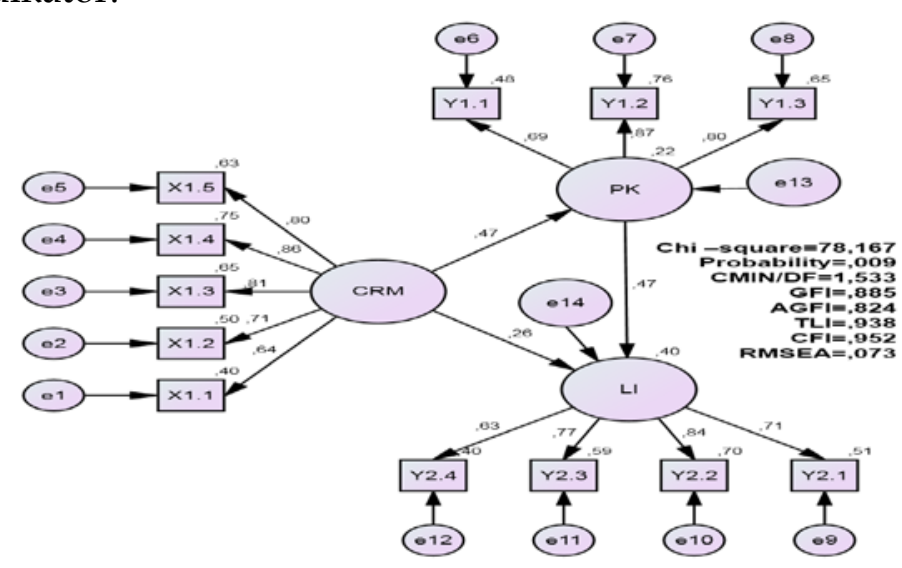

Gambar 1 : Diagram Analisis Jalur

\subsection{Hasil Pengujian Hipotesis}

Berdasarkan hasil output analisis jalur yang dilakukan, dapat diketahui tingkat signifikansi pengaruh dan nilai Critical Ratio (CR) yang merupakan nilai t-value. Hasil ini digunakan untuk pengujian hipotesis penelitian yang diajukkan sebagai berikut. 


\section{NATIONALLY ACCREDITED J OURNAL = DECREE NO, 21/E/KPT/2018}

Tabel 5. Hasil Output Analisis Jalur atau Path dengan SEM

\begin{tabular}{|c|c|c|c|c|c|}
\hline Hipotesis & Jalur & $\beta$ & C.R & $P$ & Keterangan \\
\hline H-1 & $\begin{array}{l}\text { Customers Relationship Management } \\
\rightarrow \\
\text { Product Knowledge }\end{array}$ & ,55, & 3,578 & $* * *$ & $\begin{array}{c}\text { Signifikan atau } \\
\text { Terdukung Oleh } \\
\text { Data } \\
\end{array}$ \\
\hline H-2 & $\begin{array}{l}\text { Customers Relationship Management } \\
\rightarrow \text { Loyalty Intention }\end{array}$ & ,31 & 2,175 & ,030 & $\begin{array}{c}\text { Signifikan atau } \\
\text { Terdukung Oleh } \\
\text { Data }\end{array}$ \\
\hline H- 3 & $\begin{array}{l}\text { Product Knowledge } \rightarrow \text { Loyalty } \\
\text { Intention }\end{array}$ & 47 & 3,474 & $* * *$ & $\begin{array}{c}\text { Signifikan atau } \\
\text { Terdukung Oleh } \\
\text { Data }\end{array}$ \\
\hline
\end{tabular}

\subsubsection{Pengaruh Customers Relationship Management (CRM) terhadap Product Knowledge.}

Hipotesis 1 pada penelitian ini adalah Customers Relationship Management (CRM) terhadap Product Knowledge. Sehingga semakin tinggi Customers Relationship Management (CRM), maka semakin tinggi Product Knowledge konsumen. Berdasarkan hasil pengolahan data diketahui bahwa nilai C.R (Critical Ratio) untuk pengaruh antara variabel Customers Relationship Management (CRM) terhadap Product Knowledge seperti terlihat pada Tabel 4.11 adalah sebesar 3,578 dengan nilai signifikan $p$ sebesar $\left(^{* * *}\right)$ atau tingkat signifikan $<0,001$. Kedua nilai ini menunjukkan hasil yang memenuhi syarat, yaitu diatas 1,96 untuk C.R (Critical Ratio) dan dibawah 0.05 untuk nilai probability. Sementara nilai koofisien jalur $\beta$ sebesar 0,55. Ini menunjukkan bahwa Customers Relationship Management (CRM) memiliki kontribusi serta pengaruh yang positif terhadap Product Knowledge konsumen. Sehingga dapat disimpulkan bahwa hipotesis 1 pada penelitian ini dapat didukung atau diterima.

\subsubsection{Pengaruh Customers Relationship Management (CRM) terhadap Loyalty Intention.}

Hipotesis ke 2 yakni Customers Relationship Management (CRM) terhadap Loyalty Intention, sehingga semakin tinggi Customers Relationship Management (CRM), maka semakin tinggi pula terjadinya Loyalty Intention. Dari hasil pengolahan data diperoleh nilai c.r (critical ratio) pengaruh antara Customers Relationship Management (CRM) terhadap Loyalty Intention adalah sebesar 2,175 diatas 1,96 dengan nilai signifikan $p$ sebesar 0,030; pada tingkat signifikan $p<0,05$ sementara nilai kofisien jalur $\beta$ sebesar 0,31 menunjukkan Customers Relationship Management (CRM) mempunyai pengaruh yang positif dan signifikan terhadap Loyalty Intention. Sehingga dapat di simpulkan bahwa hipotesis ke 2 didukung atau dapat diterima.

\subsubsection{Pengaruh Product Knowledge terhadap Loyalty Intention}

Hipotesis ke 3 yakni Product Knowledge terhadap Loyalty Intention, sehingga semakin tinggi Product Knowledge yang diketahui konsumen, maka semakin tinggi pula terjadinya Loyalty Intention. Dari hasil pengolahan data diperoleh nilai c.r (critical ratio) pengaruh antara Product Knowledge terhadap Loyalty Intention adalah sebesar 3,474 diatas 1,96 dengan nilai signifikan $p$ sebesar $\left(^{(* *}\right)$ atau tingkat signifikan $<0,001$ pada tingkat signifikan $p<0,05$ sementara nilai kofisien jalur $\beta$ sebesar 0,47 menunjukkan Product Knowledge mempunyai pengaruh yang positif dan signifikan terhadap Loyalty Intention. Sehingga dapat di simpulkan bahwa hipotesis ke 2 didukung atau dapat diterima. 


\section{NATIONALLY ACCREDITED J OURNAL - DECREE NO. 21/E/KPT/2018}

\subsection{Pembahasan Hasil Penelitian}

\subsubsection{Pengaruh Customers Relationship Management (CRM) terhadap Product Knowledge.}

Hasil olah data penelitian menujukan bahwa Customers Relationship Management (CRM) berpengaruh positif dan signifikan terhadap Product Knowledge. Sehingga semakin tinggi Customers Relationship Management (CRM), maka semakin tinggi Product Knowledge konsumen. Dalam penelitian ini Customers Relationship Management (CRM) diukur dengan 5 indikator pertanyaan merasa aman bertransaksi, adanya pelayanan khusus, cepat dalam merespon setiap komplain nasabah, merasa dilibatkan dalam setiap program undian berhadiah, kemudahan dalam mengakses informasi program pemasaran Bank BNI Syariah Cabang Mataram atau (teknologi). Hasil penelitian ini tidak mendukung riset yang dilakukan oleh (Rigby et al., 2002 dalam Alexandra, 2003) dimana program CRM yang diterpkan gagal dalam memberikan hasil yang diharapkan oleh konsumen terkait program pemasaran serta produk ang dipasarkan. Sementara dalam penelitian ini program CRM Bank BNI Syariah Cabang Mataram cukup memberikan kontribusi yang berarti bagi konsumen terutama dalam mengakses berbagai informasi produk serta transaksi perbankan.

Diantara program CRM tersebut misalnya melalui pemanfaatan teknologi yang dilakukan oleh pihak Bank BNI Syariah Cabang Mataram dimana dalam memberikan informasi kepada pelanggan untuk melayani nasabahnya PT. BNI Syariah Cabang Mataram menawarkan layanan hasanah lifestyle banking application diantaranya produk Wakaf Hasanah (berwakaf secara online), Migrant Mortgage (pembelian rumah untuk TKI), Umrah \& Hajj (layanan ibadah lengkap dengan map locator), halal tourism dan hasanah wallet. Melalui Hasanah Lifestyle Banking dengan memberikan one service Hasanah yang memberikan produk dan layanan sesuai syariah yang dapat diakses melalui aplikasi hasanah mobile di smartphone/gadget. Hal ini memudahkan nasabah dalam mengetahui informasi fitur-fitur layanan dan produk PT. BNI Syariah dimanapun dan kapanpun sehingga nasabah tidak perlu repot ke bank untuk bertransaksi sehingga lebih efisien.

Menurut Buttle (2007) Customer Relationship Management (CRM) sebagai suatu strategi memperoleh, mengkonsolidasi dan menganalisis data customer dan kemudian dipergunakan untuk berinteraksi dengan customers. Sementara hasil studi Ernest \& Young (2001) dari para manajer yang telah menerapkan CRM menemukan bahwa dua tantangan terbesar dalam menerapkan strategi CRM adalah isu organisasi internal (53\% responden), diikuti oleh kemampuan untuk mengakses semua informasi yang relevan (40\% responden). Ini menunjukkan bukti bahwa agar CRM berhasil, diperlukan strategi jitu bagaimana suatu perusahaan mengelola program CRM dengan maksimal sehingga memberikan hasil yang positif.

Program CRM yang baik akan terwujud apabila perusahaan mampu membangun manajemen hubungan pelanggan dengan baik misalnya dengan melakukan promosi produk yang menarik dengan memanfaatkan kecangihan teknologi internet saat ini, menginggat konsumen indonesia saat ini sangat melek teknologi berbasis digital tidak terkecuali masyarakat di Kota Mataram. melalui promosi yang efetif tersebut perusahaan dapat memberitahukan banyak informasi terkait produk-produk perusahaan kepada konsumen dan ketika konsumen memutuskan akan melakukan pembelian itu berarti konsumen tersebut telah memiliki pengetahuan terkait produk tersebut. Apakah pengetahuan tentang fitur produk, manfaat produk atau keuntungan maksimal dalam menggunakan produk Bank BNI Syariah Cabang Mataram dimasa mendatang. 
4.3.2. Pengaruh Customers Relationship Management (CRM) terhadap Loyalty Intention.

Hasil analisis data penelitian diketahui bahwa Customers Relationship Management (CRM) memiliki pengaruh yang positif dan signifikan terhadap Loyalty Intention, ini bermakna bahwa semakin baik atau tinggi Customers Relationship Management (CRM) diterapkan, maka semakin tinggi pula terjadinya Loyalty Intention konsumen pada Bank BNI Syariah Cabang Mataram. Hasil penelitian ini mendukung penelitian Amirusefi, Ahrari (2012) hasil penelitian menunjukkan bahwa ada hubungan yang signifikan antara Customer Relationship Management (CRM) dan loyalitas konsumen.

Kotler dan Armstrong (2008), berpendapat bahwa Customer Relationship Management (CRM) dapat membangun dan memelihara hubungan pelanggan yang menguntungkan dengan menghantarkan nilai dan menciptakan pelanggan yang loyal dengan berbagai keunggulan produk yang ditawarkan. Sementara menurut Foster (2008), menyatakan bahwa Fokus dari Customer Relationship Management (CRM) salah satunya untuk meningkatkan keputusan pembelian konsumen, apabila konsumen terus melakukan pembelian maka berpotensi untuk menjadi konsumen yang loyal. Penelitian Rahmadewi, et.al (2015), membuktikan bahwa Customer Relationship Management (CRM) berpengaruh signifikan terhadap keputusan pembelian ulang konsumen. Dimana, ketika konsumen melakukan pembelian ulang secara terus menerus dapat mengarah pada kecenderungan niat konsumen untuk menjadi pembeli yang loyal. Pada penelitian Maftuhah, et.al (2014), membuktikan bahwa Customer Relationship Management (CRM) berpengaruh terhadap loyalitas nasabah. Sedangkan hasil penelitian Arif \& Nurasiah (2015), membuktikan bahwa Customer Relationship Management (CRM) berpengaruh terhadap loyalitas nasabah bank. Penelitian Rahayu \& Suryanti (2014), membuktikan bahwa hubungan pelanggan berpengaruh terhadap loyalitas nasabah.

\subsubsection{Pengaruh Product Knowledge terhadap Loyalty Intention}

Berdasarkan hasil pengolahan data penelitian yang telah dilakukan oleh peneliti menujukan bahwa terdapat pengaruh yang positif dan signifikan Product Knowledge terhadap Loyalty Intention, sehingga semakin tinggi Product Knowledge yang di ketahui konsumen, maka semakin tinggi pula terjadinya Loyalty Intention pada Bank BNI Syariah Cabang Mataram. Hasil penelitian ini didukung oleh penelitian Kuncahyaningtyas dan Amron, (2015), bahwa terdapat pengaruh yang positif dan signifikan antara pengetahuan produk terhadap niat konsumen untuk kembali menggunakan jasa perbankan, dimana niat berperilaku cenderung dapat mengarahkan konsumen untuk berperilaku loyal.

Kajian empiris Isnani (2014) dan Suryanda (2016), membuktikan bahwa pengetahuan nasabah berpengaruh terhadap keputusan nasabah dalam menabung di bank syariah. Namun dalam penelitian Yuliawan (2011), pengetahuan konsumen tentang bank syariah memberikan pengaruh sangat kecil terhadap pengambilan keputusan konsumen untuk menjadi nasabah pada bank syariah. Sementara dalam penelitian ini product knowledge memberikan kontribusi pengaruh yang relatif tinggi terhadap loyalty intention konsumen pada Bank BNI Syariah Cabang Mataram. Sieben yang dikutip dalam Waluyo dan Pamungkas (2003), pengetahuan produk adalah cakupan seluruh informasi akurat yang disimpan dalam memori konsumen yang sama baiknya dengan persepsinya terhadap pengetahuan produk. Konsumen dengan pengetahuan yang lebih tinggi akan menjadi lebih realistis dalam pemilihan produk yang sesuai dengan harapannya. Dimana, semakin tinggi pengetahuan konsumen dalam pembelian suatu produk, dapat meningkatkan kemampuan konsumen untuk membuat pilihan yang lebih memuaskan. Pengetahuan konsumen tentang informasi produk yang yang lebih mendalam tentu dapat menjadi faktor utama yang sangat mempengaruhi sikap nasabah terhadap niat untuk loyal dalam menggunakan kembali produk jasa perbankan. 
Menurut Grifin (2005),bahwa konsumen yang melakukan pembelian secara berulang dan teratur yang dimana telah merasakan manfaat atas produk atau jasa yang telah diterima dari suatu perusahaan, biasanya akan berniat melakukan pembelian kembali. Dengan kata lain niat berprilaku dapat mengarah pada keinginan konsumen untuk menjadi pelanggan yang loyal. Pengetahuan produk yang dimiliki oleh konsumen sangat mempengaruhi dalam membeli suatu produk. Menurut Durianto, et.al (2001), pengetahuan yang dimiliki oleh nasabah sangat mempengaruhi sikap dan prilaku nasabah dalam mengambil sebuah keputusan, karena semakin tinggi tingkat pengetahuan tentang produk, berarti produk tersebut berada dalam benak konsumen sebelum adanya produk lain sehingga pengetahuan nasabah akan mempengaruhi keputusan pembelian. Hasil penelitian yang dilakukan oleh Safrida (2015), dimana pengetahuan produk oleh konsumen tidak berpengaruh pada niat konsumen untuk loyal. Demikian halnya dengan penelitian Rizkiana (2009) dan Octaviani (2017), product knowledge tidak berpengaruh signifikan terhadap keputusan konsumen.

\section{KESIMPULAN DAN SARAN}

\subsection{Kesimpulan}

Berdasarkan hasil pengolahan data dan pembahasan pada bab sebelumnya, sehingga dapat ditarik kesimpulan sebagai berikut.

1. Customers Relationship Management (CRM) berpengaruh positif dan signifikan terhadap Product Knowledge. Ini bermakna semakin tinggi Customers Relationship Management (CRM), maka semakin tinggi Product Knowledge konsumen.

2. Product Knowledge memiliki pengaruh yang positif dan signifikan terhadap Loyalty Intention, ini bermakna bahwa semakin tinggi Product Knowledge konsumen, maka semakin tinggi pula terjadinya Loyalty Intention konsumen pada produk Bank BNI Syariah Cabang Mataram.

3. Customers Relationship Management (CRM) memiliki pengaruh yang positif dan signifikan terhadap Loyalty Intention, ini bermakna bahwa semakin baik atau tinggi Customers Relationship Management (CRM) diterapkan, maka semakin tinggi pula terjadinya Loyalty Intention konsumen pada Bank BNI Syariah Cabang Mataram.

\subsection{Saran}

\subsubsection{Implikasi Teori}

Secara teori terdapat banyak variabel yang dapat mempengaruhi loyalty intention. Namun fokus pada penelitian ini bahwa loyalty intention dapat dipengaruhi oleh Customers Relationship Management (CRM), product knowledge. Hasil penelitian ditemukan bahwa Customers Relationship Management (CRM), dan produk knowledge dapat berpengaruh terhadap loyalty intention, serta Customers Relationship Management (CRM), berpengaruh terhadap produk knowledge sehingga hasil temuan tersebut dapat menjadi rujukan ilmiah bagi perkembangan keilmuan dibidang pemasaran serta menjadi acuan bagi penelitipeneliti dimasa yang akan datang.

\subsubsection{Implikasi Praktis}

Secara praktis, penelitian ini berkontribusi pada pengambilan kebijakan Management bagi pihak-pihak yang berkepentingan terutama Bank BNI Syariah Cabang Mataram diantaranya sebagai berikut :

1. Bank BNI Syariah Cabang Mataram diharapkan untuk lebih meningkatkan lagi penerapan strategi Customers Relationship Management (CRM) dalam menjalin kemitraan dengan pelanggan dengan memahami dan memenuhi harapan setiap 
nasabah sehingga memberikan informasi secara menyeluruh tentang atribut produk serta manfaat produk perbankan kepada nasabah.

2. Diharapkan kepada Bank BNI Syariah Cabang Mataram terus melakukan berbagai inovasi dan terobosan dengan memanfaatkan era teknologi digital terutama dalam meningkatkan pelayanan jasa kepada konsumen sehingga konsumen semakin loyal ditenggah semakin kompetitifnya persaingan pada industri perbankan yang cenderung berubah secara dinamis dari waktu ke waktu.

3. Bagi peneliti selanjunya agar kembali meneliti penelitian yang serupa dengan terutama pengaruh Customers Relationship Management (CRM) terhadap Product Knowledge, karena masih sangat sedikit penelitian terdahulu yang mencoba mengetahui hubungan keduannya dengan objek, jumlah sampel, alat statistik yang berbeda.

\subsubsection{Keterbatasan Penelitian dan saran untuk penelitian yang akan datang}

Keterbatasan penelitian ini adalah penelitian ini hanya meneliti pengaruh Customers Relationship Management (CRM), Product Knowledge dan Loyalty Inetntion (studi kasus pada nasabah Bank BNI Syariah Cabang Mataram) dengan jumlah sampel 100 responden dengan rentang lama menjadi nasabah bank kurang dari satu tahun. Untuk itu disarankan kepada penelitian yang akan datang untuk kembali meneliti penelitian ini dengan menambahkan variabel-variabel lain diluar penelitian ini dengan objek, jumlah sampel dan alat analisis data yang berbeda dalam scope yang lebih luas, sehingga dapat di perbandingkan dan diperoleh hasil temuan yang lebih beragam.

\section{DAFTAR PUSTAKA}

Amirusefi, R., (2012), Survey Relationship Between Customer Relationship Management and Service Quality, Satisfaction and Loyalty (Case Study Mellat Bankof - Iran), Jurnal of American Science.

Armstrong, G., (2004), Principles of Marketing.10th ed.New Jersey: Prentice-Hall, Inc.

Arif, M.N.R.A dan Nurasiah, T., (2015), Customer Relationship Management dan Pengaruhnya Terhadap Loyalitas Nasabah Bank: Studi Pada Bank Muamalat Indonesia. Jurnal Bisnis dan Manajemen 5 (1).

Bielen, (2007), Waiting Time Influence on The Satisfaction-Loyalty Relationship in Services, Managing Services Quality, Vol.17 No.2.

Buttle, (2007). Customer Relationship Management (Manajemen Hubungan Pelanggan) : Concept and Tools. Bayumedia Publishing, Malang.

Durianto., (2001), Strategi Menaklukkan Pasar Melalui Riset Ekuitas dan Perilaku Merek, Jakarta: Gramedia Pustaka Utama.

Ernest \& Young (2001), Eighth annual special report on technology in banking and financial services. Press Release Archive Canadian Fact Sheet.

Ferdinand, Augusty T. (2014), Metode Penelitian Manajemen. Edisi V. Semarang: Bp Undip.

Fanani (2014), Pengaruh Customer Relationship Management Terhadap Kepuasan Dan Loyalitas Nasabah .student journal ub.ac.id.

Foster, (2008), Manajemen Ritel. Bandung: Alfabeta.

Griffin, Jill., (2002), Customer Loyalty How to Earn It, How to Keep It. Kentucky: McGraw-Hill. Hair, J.F. (2010), Multivariate Data Analysis. Edisi 9. New Jersey: Pearson Education.

Isnani, W.,(2014), Pengaruh Pengetahuan Konsumen terhadap Keputusan Menjadi Nasabah Pada PT. Bank Muamalat Indonesia Tbk Cabang Medan. Jurnal Manajemen Perbankan dan Keuangan. 


\section{NATIONALLY ACCREDITED JOURNAL = DECREE NO, 21/E/KPT/2018}

Kuncahyaningtyas., (2015), Pengaruh Kualitas Pelayanan, Pengetahuan dan Kepuasan Bisnis.

Maftuhah, et, el, (2014), Pengaruh Customer Relationship Management (CRM) Terhadap Kepuasan Dan Loyalitas nasabah, Universitas Jember. Artikel Ilmiah Mahasiswa.

Mokodongan, A., (2010), Analisis Penerapan Program Customer Relationship Management Hubungannya Dengan Loyalitas Pelanggan (Studi Kasus di Swiss Belhotel Maleosan Manado). Jurnal INOVASI. 7 (4): pp240-171.

Yuliawan, E., (2011), Pengaruh Pengetahuan Konsumen Mengenai Perbankan Syariah Terhadap Keputusan Menjadi Nasabah Pada PT. Bank Syariah Cabang Bandung. Jurnal Wira Ekonomi Mikroskil. 1 (1): pp21-30.

Oktariana, dkk, (2010), Faktor-Faktorcustomer Relationshipmanagement (Manajemen Hubungan Pelanggan) Dalam Mewujudkan Kepuasan Anggota Dandampaknya Terhadap Loyalitas Anggota. (Survey pada Anggota Koperasi Nusantara Cabang Malang di Kantor Pos Besar Malang) Fakultas Ilmu Administrasi Universitas Brawijaya Malang.

Rahayu, B.S., dan Saryanti, E., (2014), Pengaruh Kualitas Pelayanan, Hubungan Pelanggan dan Citra Perusahaan Terhadap Loyalitas Melalui Kepuasan Nasabah. Jurnal Advance, 1 (2).

Rigby, D. K., Reicheld, F. F., \& Schefter, P. (2002), Avoid the four perils of CRM. Harvard Business Review.

Satria, (2013), Analisis Hubungan Antara Customer Relationship Management (CRM), Relationship Quality (RQ), Jurnal Teknik Pomits Vol. 2, No. 1, (2013) ISSN: 2337-3539 (2301-9271 Print).

Suryanda, A., (2016), Analisis Keputusan Nasabah Dalam Menabung (Pendekatan Model Logistik Studi pada Bank Syariah di Kota Surakarta). Jurnal Manajemen Ekonomi dan Bisnis Universitas Muhammadiyah Surakarta.

Waluyo, P., dan Pamungkas, A., (2003), Analisis Perilaku Brand Switching Konsumen dalam Pembelian Produk Handphone di Semarang. Jurnal Bisnis dan Ekonomi. 